\title{
Impact Response and Strength Reliability of Green High Performance Fibre Reinforced Concrete Subjected to Freeze-thaw Cycles in NaCl Solution
}

\section{Murali GUNASEKARAN ${ }^{1}$ *, Muthulakshmi THANGAVEL ${ }^{2}$, Nycilin Karunya NEMICHANDRAN ${ }^{2}$, Iswarya RAVIKUMAR ${ }^{2}$, Hannah Jennifer GLARANCE ${ }^{2}$, Karthikeyan KOTHANDAPANI ${ }^{3}$}

\author{
${ }^{1}$ School of Civil Engineering, SASTRA University, Thanjavur, India \\ ${ }^{2}$ School of Civil Engineering, SASTRA University, Thanjavur, India \\ ${ }^{3}$ SMBS, VIT University, Chennai, Tamil Nadu, India \\ crossref http://dx.doi.org/10. 5755/j01.ms.23.4.17334
}

Received 25 December 2016; accepted 18 March 2017

\begin{abstract}
A drop-weight impact test was conducted to evaluate the impact resistance of Green High Performance Plain Concrete (GHPPC) and Green High Performance Fibre Reinforced Concrete (GHPFRC) subjected to freeze-thaw cycles in water containing $3.0 \% \mathrm{NaCl}$ solution. The green high performance concrete mixtures were prepared using $10 \%$ of micro silica as cement replacement, $30 \%$ of copper slag as fine aggregate replacement and hooked end steel fibres were incorporated at $1.0 \%$ volume fraction. All the specimens were frozen and thawed for 25 cycles, following which the impact strength of the frozen and thawed specimens was determined. Due to the variations in impact test results, a reliability analysis was carried out using two parameter Weibull distribution and its Weibull parameters were determined using two methods viz., Energy pattern factor method (EFM) and Method of Moments (MOM). Furthermore, impact strength in terms of reliability was reported using the average value of Weibull parameters obtained from these two methods. The results revealed that impact resistance of GHPPC and GHPFRC specimens subjected to 25 cycles of freeze and thaw in water containing 3\% $\mathrm{NaCl}$ solution was significantly reduced.
\end{abstract}

Keywords: green concrete, fibre, impact strength, Weibull parameter, reliability.

\section{INTRODUCTION}

Enhancing the impact resistances of the civil and/or military infrastructure has attracted the attention of researchers to a greater extent $[1,2]$. Concrete is a brittle material (low ductility) and due to its low crack prevention capacity, depleted tensile strength; exhibits severe damage [3] when subjected to impact loading [4]. The low ductility of concrete has been overcome by using the techniques of addition of various types of fibres $[5,6]$, especially steel fibres into the concrete mixtures [7, 8]. Furthermore, adding fibres reduces the possibility of spalling and scabbing failures thereby improving its tensile strength [9], deformability [10], the crack and pore-bridging capacities of the concrete [11].

In cold regions, concrete structures are susceptible to freeze and thaw cycling due to significant seasonal variations of temperature and humidity, which can reduce its durability leading to cracks and structural deterioration [12]. This deterioration triggered by freeze-thawing can be of two different forms: internal destruction such as growth of internal cracks and disintegration; surface cracking [13] such as removal of small pieces of mortar within the surface region.

Usage of deicer salt to melt of prevent the ice formation has been identified to cause severe scaling damage on the surface of fibrous and non-fibrous concrete. The efficiency of concrete incorporating fibres in structural members is generally based on the mechanical properties of concrete [14]. Nevertheless, the resistance of concrete under frost has not yet been explored widely. Some of the earlier researches on the Fibre Reinforced Concrete (FRC) exposed to frost displayed dissimilar results owing to differences in constituting materials of concrete, several types of incorporating fibres and various test methods involved. However, the concrete incorporating short fibres of length $3 \mathrm{~mm}$ exhibited comparatively less damage. Also, the study carried out by Sun et al. [15] and Mu et al. [16] revealed that steel fibres of length $20 \mathrm{~mm}$ provided a greater resistance against the internal destruction of concrete under frost and this was assessed based on the differences in dynamic modulus of elasticity. A similar trend was noticed by Niu et al. [17] while using steel fibres of length $30 \mathrm{~mm}$. Zhang et al., [18] investigated the flexural impact response of steel FRC exposed to $0,100,150,200$ freeze-thaw cycles in $3.0 \% \mathrm{NaCl}$ solution. The effect of freeze-thaw cycles on the final impact strength of steel FRC was significantly less. Also, for the freeze - thaw cycles not greater than 200, the variations in initial impact strength was smaller.

The effect on FRC due to low velocity impact has been focused in various experimental, numerical and analytical investigations [19-21] and some important results are obtained; though the FRC's long-term behaviour under freeze-thaw cycles was considered to be of major importance [22]. However, in practice, the combined effect of mechanical stress, physical and chemical attack leads to

\footnotetext{
* Corresponding author. Tel.: +91 9944224485.

E-mail address: murali_220984@yahoo.co.in (G. Murali)
} 
the deterioration of FRC. In general, the results obtained from distinct tests will be uncertain in nature and hence it becomes vital to study the properties of FRC subjected to the joint action of two or more deterioration mechanisms [23]. However, the scattered results of drop weight impact test owing to nonhomogeneous condition of the concrete visual identification of the first crack and failure; the applied load was a single point of impact which might befall either a hard particles of coarse aggregate or on a soft area of mortar; height of the drop hammer is difficult to control exactly due to the handmade process; the free falling of the drop hammer can be influenced by the initial hand triggered work, so the experimental result can be controlled by the man-made factors $[24,25]$. Therefore, a statistical analysis is the best technique to analyse the variation in drop weight test. Thus, the impact responses of FRC subjected to 25 freeze-thaw cycles in $3.0 \% \mathrm{NaCl}$ solution were investigated experimentally and statistically in this paper.

\section{EXPERIMENTAL PROGRAM}

\subsection{Materials}

Ordinary portland cement 53 grade conforming to IS 12269-1987 [26], natural river sand conforming to zone II grading of IS: 383:1970 [27] with a specific gravity of 2.66, copper slag conforming to zone II, the chemical composition of copper slag and micro silica are presented in Table 1. Crushed granite coarse aggregate of specific gravity 2.72 with maximum size of $12 \mathrm{~mm}$, hooked end steel fibres of length $30 \mathrm{~mm}$ and diameter $0.6 \mathrm{~mm}$ with an aspect ratio of 40. High commercial super plasticizer complast SP430 DIS Sulphonated napthalene formaldehyde, were used in this study.

\subsection{Details of mixtures}

In this research, two concrete mixes (plain concrete (PC) and FRC) were designed with water/cement ratio (W/C) of 0.34 . The cement content of $410 \mathrm{~kg} / \mathrm{m}^{3}$ was replaced by $10 \%$ of micro silica and fine aggregate was replaced by $30 \%$ of copper slag. In addition, the concrete incorporated with hooked end steel fibres with $1.0 \%$ volume fraction. Based on the optimized particle packing model, the developed green high performance concrete mixtures are listed in Table 2.

\subsection{Mixing procedure and specimens}

Initially, the cement with micro silica and fine aggregate with copper slag were mixed for 1 minute, and half of the mixing water and superplastizer were added to the mix and then it was mixed again for 2 minutes. Following the remaining water was added to the mix along with coarse aggregate and mixed for 5 minutes. Finally, fibres were added at $1.0 \%$ to the mixture and the mixing was done for 5 minutes. From the mix, cylindrical discs of size 100 diameter and $50 \mathrm{~mm}$ height were prepared for the freeze and thaw test followed by impact tests after 28 days curing.

\subsection{Freeze and thaw test}

In this paper, PC and FRC specimens were subjected to 25 cycles of freezing and thawing in water containing $3 \%$ $\mathrm{NaCl}$ solution in accordance with procedure suggested by ASTM C666 [28]. In single cycle, alternatively the temperature of the specimens was lowered from $4 \pm 2{ }^{\circ} \mathrm{C}$ to $-18 \pm 2{ }^{\circ} \mathrm{C}$ and again raised to $4 \pm 2{ }^{\circ} \mathrm{C}$ within $2.0-4.0$ hours. For this test, tap water with $3 \% \mathrm{NaCl}$ solution (by weight) was used.

\subsection{Impact test}

The drop weight test was carried out by dropping a weight repeatedly on $100 \mathrm{~mm}$ diameter and $50 \mathrm{~mm}$ height cylindrical specimen based on modification recommended by ACI Committee 544 [29] as shown in Fig. 1. In this modified impact test, a $4.45 \mathrm{~kg}$ weight was dropped repeatedly from a $457 \mathrm{~mm}$ height on the top surface of the cylindrical specimens. For each specimen, the number of blows required to cause the failure was noted as failure strength.

Table 1. Chemical composition of micro silica and copper slag

\begin{tabular}{|c|c|c|c|c|c|c|c|c|c|c|c|c|}
\hline \multicolumn{1}{|c|}{ Materials } & $\begin{array}{c}\mathrm{SiO}_{2} \\
\%\end{array}$ & $\begin{array}{c}\mathrm{CaO} \\
\%\end{array}$ & $\begin{array}{c}\mathrm{Al}_{2} \mathrm{O}_{3} \\
\%\end{array}$ & $\begin{array}{c}\mathrm{Fe}_{2} \mathrm{O}_{3} \\
\%\end{array}$ & $\begin{array}{c}\mathrm{CuO} \\
\%\end{array}$ & $\begin{array}{c}\mathrm{Na}_{2} \mathrm{O} \\
\%\end{array}$ & $\begin{array}{c}\mathrm{TiO}_{2} \\
\%\end{array}$ & $\begin{array}{c}\mathrm{K}_{2} \mathrm{O} \\
\%\end{array}$ & $\begin{array}{c}\mathrm{Mn}_{2} \mathrm{O}_{3} \\
\%\end{array}$ & $\begin{array}{c}\mathrm{SO}_{3} \\
\%\end{array}$ & $\begin{array}{c}\mathrm{Cl} \\
\%\end{array}$ & $\begin{array}{c}\mathrm{Other}^{2} \\
\%\end{array}$ \\
\hline Copper Slag & 25.84 & 0.15 & 0.22 & 68.59 & 1.2 & 0.58 & 0.41 & 0.28 & 0.22 & 0.11 & 0.018 & - \\
\hline Micro Silica & 96 & 0.2 & 0.6 & 1.2 & - & - & - & - & - & - & - & 2 \\
\hline
\end{tabular}

Table 2. Recipes of developed green high performance concrete

\begin{tabular}{|c|c|c|c|c|c|c|c|c|c|c|c|}
\hline $\begin{array}{l}\text { Mix } \\
\text { No. }\end{array}$ & Series & $\mathrm{W} / \mathrm{C}$ & $\begin{array}{c}\mathrm{W}, \\
\mathrm{kg} / \mathrm{m}^{3}\end{array}$ & $\begin{array}{c}\text { Cement, } \\
\mathrm{kg} / \mathrm{m}^{3}\end{array}$ & $\begin{array}{c}\text { Fine } \\
\text { agg., } \\
\mathrm{kg} / \mathrm{m}^{3}\end{array}$ & $\begin{array}{c}\text { Coarse } \\
\text { agg., } \\
\mathrm{kg} / \mathrm{m}^{3}\end{array}$ & $\begin{array}{c}\text { Micro } \\
\text { silica, \% }\end{array}$ & $\begin{array}{c}\text { Copper } \\
\text { slag, \% }\end{array}$ & $\begin{array}{c}\text { Volume } \\
\text { fraction, } \\
\mathrm{V}_{\mathrm{f}}\end{array}$ & $\begin{array}{c}\text { Freeze } \\
\text { and thaw, } \\
\text { cycle }\end{array}$ & \begin{tabular}{c} 
Sp, \% \\
\hline 1
\end{tabular} \\
\hline GHPPC & 0.34 & 140 & 410 & 801 & 1130 & 10 & 30 & - & - & 0.6 \\
\hline 3 & GHPPC-FT & 0.34 & 140 & 410 & 801 & 1130 & 10 & 30 & - & 25 & 0.6 \\
\hline 4 & GHPFRC & 0.34 & 140 & 410 & 801 & 1130 & 10 & 30 & 1.0 & - & 1.0 \\
\hline
\end{tabular}




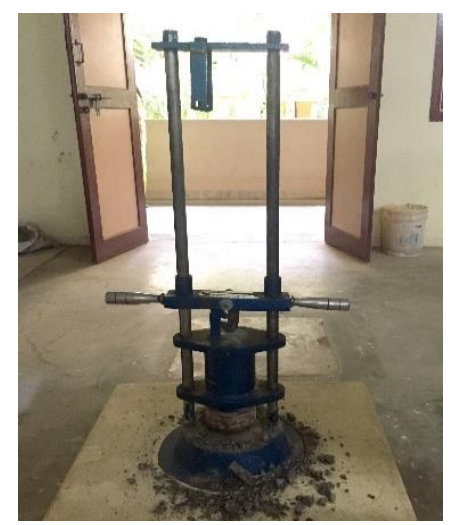

Fig. 1. Impact test device

\section{RESULTS AND DISCUSSION}

\subsection{Impact strength}

The impact strength results of sixteen specimens from each mix are presented in Table 3 . Adding $1 \%$ volume fraction of steel fibre to the green high performance fibre reinforced concrete (GHPFRC) increases its impact failure strength by $193 \%$ when compared to green high performance plain concrete (GHPPC). Table 3 shows the comparison between impact failure energy of GHPPC and GHPFRC mixes before and after 25 freeze-thaw (FT) cycles. As observed from the Table 3, the impact failure strength gradually decreases after being exposed to freezethaw cycling.

Table 3. Impact strength of specimens under drop weight

\begin{tabular}{|c|c|c|c|c|}
\hline \multirow{2}{*}{ S. No } & \multicolumn{4}{|c|}{ Number of blows needed for failure } \\
\cline { 2 - 5 } & GHPPC & GHPPC-FT & GHPFRC & GHPFRC-FT \\
\hline 1 & 12 & 11 & 45 & 59 \\
\hline 2 & 16 & 19 & 56 & 61 \\
\hline 3 & 18 & 20 & 66 & 62 \\
\hline 4 & 20 & 22 & 74 & 69 \\
\hline 5 & 21 & 24 & 84 & 73 \\
\hline 6 & 22 & 27 & 86 & 73 \\
\hline 7 & 26 & 29 & 90 & 80 \\
\hline 8 & 28 & 31 & 95 & 85 \\
\hline 9 & 32 & 35 & 99 & 87 \\
\hline 10 & 33 & 36 & 101 & 87 \\
\hline 11 & 35 & 39 & 101 & 91 \\
\hline 12 & 36 & 41 & 118 & 92 \\
\hline 13 & 37 & 43 & 119 & 92 \\
\hline 14 & 40 & 46 & 125 & 97 \\
\hline 15 & 41 & 52 & 133 & 102 \\
\hline 16 & 49 & 54 & 159 & 108 \\
\hline Mean & 33 & 29 & 97 & 82 \\
\hline$\sigma$ & 12.36 & 10.40 & 29.56 & 14.98 \\
\hline$\sigma-$ standard deviation & & \\
\hline
\end{tabular}

The average number of blows required to cause failure was 33 and 97 in case of GHPPC and GHPFRC respectively, while, the average number of blows required to cause failure after its exposure to 25 freeze- thaw cycles in $3 \% \mathrm{NaCl}$ solution was 29 and 82 respectively. Therefore, the decrease in the impact failure strength of GHPPC and GHPFRC after 25 freeze-thaw cycles were $12 \%$ and $15 \%$ respectively. It was found that all the GHPPC specimens were broken into two pieces under impact load and hence experienced brittle failure. On the other hand, multiple cracks were observed in the case of GHPFRC specimens and it did not break into two pieces. Thus, it can be concluded that, by adding fibres in concrete, the failure mode was altered from a single large crack to multiple cracks, which reveals the valuable effects of fibre reinforced concrete when exposed to impact loading.

\subsection{Statistical methods for determining the Weibull parameters}

Several studies reported the large scatter in the drop weight test results $[24,25]$ and this may be attributed to the fact that drop weight test is influenced by handmade work and hence the test results would also be greatly influenced by man made errors. This leads to the necessity of employing statistical analyses for their safe utilization in design of structures. Table 3 , shows that impact strength is a random variable and in order to evaluate the accurate impact strength of GHPPC and GHPFRC before and after freeze and thaw it is essential to analyse the results data, statistically. The Weibull distribution is broadly used in reliability studies; in recent years, several modifications have been developed which greatly enlarged the applications [30, 31]. Based on impact strength test results two parameter Weibull distribution can be defined as a probability density function $\mathrm{F}(\mathrm{N})$ as given:

$F(N)=1-\exp \left[-\left(\frac{N}{\alpha}\right)\right]^{\gamma}$,

where $\gamma$ and $\alpha$ are the shape and scale parameters respectively and $\mathrm{N}$ is the impact strength (Number of blows causing failure). For determining the Weibull parameters two numerical methods has been used. The impact strength $\mathrm{N}_{\mathrm{R}}$ in form of probability of survival $(R)$ i.e, reliability.

$N_{R}=\alpha\left(-\ln (R)^{\frac{1}{\gamma}}\right)$

\subsubsection{Energy pattern factor method}

The energy pattern factor method is related to the averaged data of impact strength and is defined by the following equations.

$\operatorname{Epf}=\frac{\overline{N^{3}}}{\bar{N}^{3}}$

$\gamma=1+\frac{3.69}{(E p f)^{2}}$

$\bar{N}=\alpha \Gamma(1+1 / \gamma)$,

where Epf is the energy pattern factor and the gamma function is defined by

$\Gamma(\mathrm{x})=\int_{0}^{\infty} t^{x-1} \exp (-t) d t$.

\subsubsection{Method of moments (MOM)}

The dimensionless Weibull and scale parameters can be calculated as follows [40] and $\alpha$ is obtained from Eq. 5:

$\gamma=\left(\frac{0.9874}{\frac{\sigma}{\bar{N}}}\right)^{-1.086}$. 


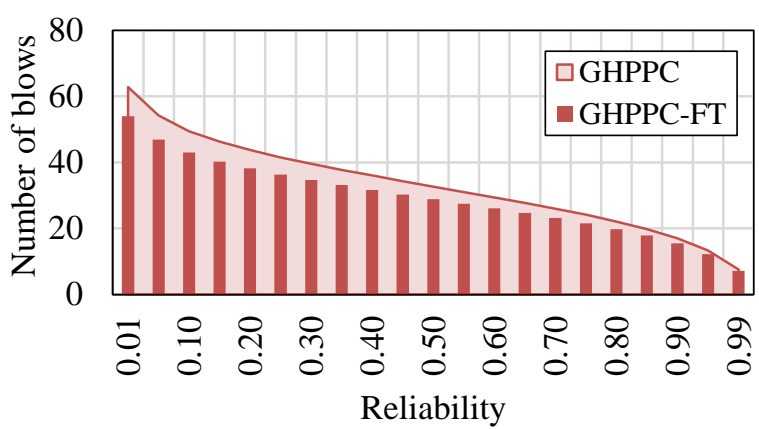

a

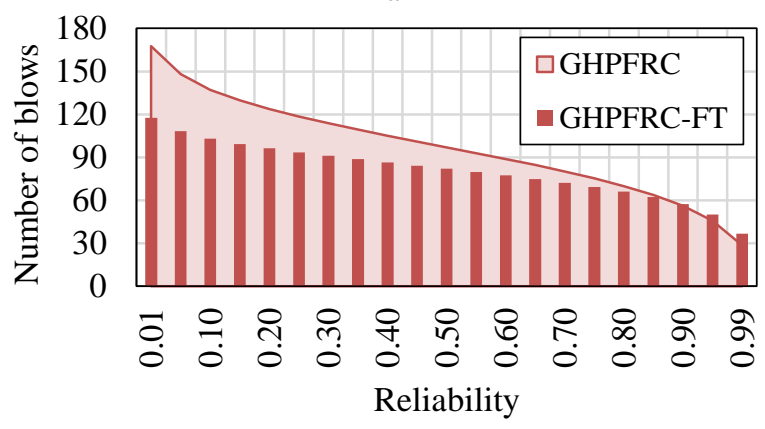

$\mathrm{b}$

Fig. 2. Number of blows in terms of reliability: a-GHPPC and GHPPC-FT; $b$ - GHPFRC and GHPFRC-FT

The Weibull parameter values estimated using two different statistical methods are presented in Table 4.

Table 4. Estimated Weibull parameters

\begin{tabular}{|c|c|c|c|c|}
\hline \multirow{2}{*}{ Mix } & \multirow{2}{*}{ Parameters } & \multicolumn{2}{|c|}{ Methods } & \multirow{2}{*}{ Average } \\
\cline { 2 - 4 } & & EFM & MOM & \\
\hline \multirow{2}{*}{ GHPPC } & $\gamma$ & 2.89 & 2.91 & 2.90 \\
\cline { 2 - 5 } & $\alpha$ & 37.11 & 37.11 & 37.11 \\
\hline \multirow{2}{*}{ GHPPC-FT } & $\gamma$ & 2.99 & 3.06 & 3.03 \\
\cline { 2 - 5 } & $\alpha$ & 32.62 & 32.59 & 32.61 \\
\hline \multirow{2}{*}{ GHPFRC } & $\gamma$ & 3.30 & 3.63 & 3.47 \\
\cline { 2 - 5 } & $\alpha$ & 108.07 & 107.59 & 107.83 \\
\hline \multirow{2}{*}{ GHPFRC-FT } & $\gamma$ & 4.10 & 6.44 & 5.27 \\
\cline { 2 - 5 } & $\alpha$ & 90.91 & 84.87 & 87.89 \\
\hline
\end{tabular}

The average value of Weibull parameter obtained from the two methods was used for reliability analysis. The number of blows required to cause failure in terms of reliability $\mathrm{N}_{R}$ is calculated by using Eq. 2 and the plot obtained for both GHPPC and GHPFRC is shown in Fig. 2. For example, at 0.90 reliability level the number of blows required cause failure of GHPPC, GHPPC-FT, GHPFRC and GHPFRC-FT specimens, in terms of reliability were 13, 12,45 and 53 respectively. Similarly, at 0.50 reliability level the number of blows for causing failure of GHPPC, GHPPC-FT, GHPFRC and GHPFRC-FT specimens were 32, 28, 94 and 81 respectively. This method discards the assessment of average values of the experimental test results and in this respect, Weibull distribution enables the designers to safely choose the impact strength (Number of blows) values for design calculations for the desired reliability/probability of failure.

\section{CONCLUSIONS}

It is critical to choose the design values based on the drop weight test results owing to its lack of reliability and it might maximise the probability of failure. In this paper, a proficient, practical and enhanced method was employed to analyse the variations in drop weight test results using two different statistical methods of two parameter Weibull distribution and the impact strength was offered in terms of reliability. Experimental and statistical analysis has yielded the following conclusions;

1. The impact failure strength of GHPFRC increases by $193 \%$ when compared to GHPPC.

2. When the concrete is exposed to 25 cycles of freezethaw, the impact failure strength decreases by $12 \%$ and $15 \%$ in case of GHPPC and GHPFRC respectively. The number of blows required to cause failure at 0.90 reliability level were $13,12,45$ and 53 for the mixes GHPPC, GHPPC-FT, GHPFRC and GHPFRC-FT respectively.

3. These statistical methods prove to be very effective in determining the impact strength values accurately. Also, this method discards the assessment of average values of the experimental test results and in this respect Weibull distribution enables the designers to safely choose the impact strength (Number of blows) value for design calculation in terms of a reliability function.

\section{Acknowledgments}

An author gratefully acknowledges support by Sastra University.

\section{REFERENCES}

1. Yu, R., van Beers, L., Spiesz, P., Brouwers, H.J.H. Impact Resistance of a Sustainable Ultra-High Performance Fibre Reinforced Concrete (Uhpfrc) Under Pendulum Impact Loadings Construction and Building Materials 107 2016: pp. $203-215$. https://doi.org/10.1016/j.conbuildmat.2015.12.157

2. Pavlovic, A., Fragassa, C., Disic, A. Comparative Numerical and Experimental Study of Projectile Impact on Reinforced Concrete Composites Part B 108 2017: pp. $122-130$.

3. Sukontasukkul, P., Jamnam, S., Rodsin, K., Banthia, N. Use of Rubberized Concrete as a Cushion Layer in Bulletproof Fiber Reinforced Concrete Panels Construction and Building Materials 41 2013: pp. 801-811.

4. Alavi Nia, A., Hedayatian, M., Nili, M., Afrough Sabet, V. An Experimental and Numerical Study on How Steel and Polypropylene Fibers Affect the Impact Resistance in FiberReinforced Concrete International Journal of Impact Engineering 46 2012: pp. 62-73. https://doi.org/10.1016/j.ijimpeng.2012.01.009

5. Murali, G., Santhi, A.S., Mohan Ganesh, G. Loss of Mechanical Properties of Fiber-Reinforced Concrete Exposed to Impact Load Romanian Journal of Materials 46 (4) 2016: pp. $491-496$.

6. Murali, G., Santhi, A.S., Mohan Ganesh, G. Empirical Relationship Between the Impact Energy and Compressive Strength for Fibre Reinforced Concrete Journal of Scientific and Industrial Research 73 2014: pp. 469-473.

7. Wang, H.T., Wang, L.C. Experimental Study on Static and Dynamic Mechanical Properties of Steel Fiber Reinforced Lightweight Aggregate Concrete Construction and Building Materials 38 2013: pp. 1146-1151. 
8. Yazici, S., Arel, H.S., Tabak, V. The Effects of Impact Loading on the Mechanical Properties of the Sfrcs Construction and Building Materials 41 2013: pp. 68-72.

9. Mohammadi, Y., Singh, S.P., Kaushik, S.K. Properties of Steel Fibrous Concrete Containing Mixed Fibres in Fresh and Hardened State Construction and Building Materials 22 2008: pp. 956-965.

10. Bolat, H., Simsek, O., Çullu, M., Durmus, G., Can, Ö. The Effects of Macro Synthetic Fiber Reinforcement Use on Physical and Mechanical Properties of Concrete Composites Part B: Engineering 61 2014: pp. 191-198.

11. Qian, C.X., Stroeven, P. Development of Hybrid Polypropylene-Steel Fibre Reinforced Concrete Cement Concrete Research 30 2000: pp. 63-69. https://doi.org/10.1016/S0008-8846(99)00202-1

12. Liu, K., Yan, J., Hua, Q., Sun, Y., Zou, C. Effects of Parent Concrete and Mixing Method on the Resistance to Freezing and Thawing of Air-Entrained Recycled Aggregate Concrete Construction and Building Materials 106 2016: pp. $264-273$.

https://doi.org/10.1016/j.conbuildmat.2015.12.074

13. Sun, Z., Scherer, G.W. Effect of Air Voids on Salt Scaling and Internal Freezing Cement Concrete Research 40 2010: pp. 260-270.

14. Voit, K., Kirnbauer, J. Tensile Characteristics and Fracture Energy of Fiber Reinforced and Non-Reinforced Ultra-High Performance Concrete (Uhpc) International Journal Fracture 188 2014: pp. 147-157. https://doi.org/10.1007/s10704-014-9951-7

15. Sun, W., Zhang, Y.M., Yan, H.D., Mu, R. Damage and Damage Resistance of High Strength Concrete Under the Action of Load And Freeze-Thaw Cycles Cement Concrete Research 29 1999: pp. 1519-1523. https://doi.org/10.1016/S0008-8846(99)00097-6

16. Mu, R., Miao, C., Luo, X., Sun, W. Interaction Between Loading, Freeze-Thaw Cycles, and Chloride Salt Attack of Concrete with and Without Steel Fiber Reinforcement Cement Concrete Research 32 2002: pp. 1061-1066.

17. Niu, D., Jiang, L., Bai, M., Miao, Y. Study of the Performance of Steel Fiber Reinforced Concrete to Water and Salt Freezing Condition Materials Design 44 2013: pp. $267-273$.

18. Zhang, W., Chen, S., Zhang, N., Zhou, Y. Low-Velocity Flexural Impact Response of Steel Fiber Reinforced Concrete Subjected to Freeze-Thaw Cycles on $\mathrm{NaCl}$ Solution Construction and Building Materials 101 2015: pp. 522-526. https://doi.org/10.1016/j.conbuildmat.2015.09.045

19. Farnam, Y., Mohammadi, S., Shekarchi, M. Experimental and Numerical Investigations of Low Velocity Impact Behavior of High-Performance Fiber Reinforced Cement
Based Composite International Journal of Impact Engineering 37 (2) 2010: pp. 220-229.

https://doi.org/10.1016/j.ijimpeng.2009.08.006

20. Sohel, K.M.A., Richard Liew, J.Y., Koh. C.G. Numerical Modelling of Lightweight Steel-Concrete-Steel Sandwich Composite Beams Subjected to Impact Thin-Walled Structures 94 2015: pp. 135-146.

21. Verma, M., Prem, P.R.,

Rajasankar, J., Bharatkumar, B.H. On Low-Energy Impact Response of Ultra-High Performance Concrete (UHPC) Panels Materials and Design 92 2016: pp. 853-865. https://doi.org/10.1016/j.matdes.2015.12.065

22. Niu, D.T., Jiang, L., Bai, B., Miao, Y.Y. Study of the Performane of Steel Fiber Reinforced Concrete to Water and Salt Freezing Condition Material Design 44 2013: pp. 267-273.

23. Miao, C.W., Mu, R., Tian, Q., Sun, W. Effect of Sulfate Solution on the Frost Resistance of Concrete with and Without Steel Fiber Reinfocement Cement Concrete Research 32 (1) 2002: pp. 31-34.

24. Chen, X., Ding, Y., Azevedo, C. Combined Effect of Steel Fibres and Steel Rebars on Impact Resistance of High Performance Concrete Journal of Central South University Technology 18 2011: pp. 1677-1684.

25. Murali, G., Santhi, A.S., Mohan Ganesh, G. Impact Resistance and Strength Reliability of Fiber-Reinforced Concrete in Bending Under Drop Weight Impact Load International Journal of Technology 5 (2) 2014: pp. $111-120$.

26. IS 12269-1987. Indian Standard Ordinary Portland Cement, 53 Grade-Secifications.

27. IS 383-1970. Indian Standard Specification for Coarse and Fine Aggregates from Natural Sources for Concrete, 1970.

28. AST C666/C666M. Standard test method for resistance of concrete torapid freezing and thawing. West Conshohocken, Pa: American Society for Testing and Materials; 2008.

29. ACI Committee 544. State-of-the-art report on fiberreinforced concrete. ACI committee 544 report 544.1R-96. Detroit: American Concrete Institute; 1996.

30. Akdag, A., Guler, O. A Novel Energy Pattern Factor Method for Wind Speed Distribution Parameter Estimation Energy Conversion and Management 106 2015: pp. 1124-1133.

31. Zhang, J., Chen, W., Wang, C., Chen, X., Cheng, G., Qiu, Y., Wu, H. An Improved Modeling for Life Prediction of High-Power White Led Based on Weibull Right Approximation Method Microelectronics Reliability 59 2016: pp. $49-54$.

32. Kumar, K.S.P., Gaddada, S. Statistical Scrutiny of Weibull Parameters for Wind Energy Potential Appraisal in the Area of Northern Ethiopia Renewables 2 (14) 2015: pp. 1-15. 